\title{
Blood Pressure Management for Stroke Prevention and in Acute Stroke
}

\author{
Keun-Sik Hong \\ Department of Neurology, Ilsan Paik Hospital, Inje University, Goyang, Korea
}

Elevated blood pressure (BP) is the leading modifiable risk factor for stroke and the benefit of BP lowering therapy on the stroke risk reduction is well established. The optimal BP target for preventing stroke and other vascular events have been controversial, but the evidences from epidemiological studies and randomized controlled trials (RCTs) support intensive BP lowering for greater vascular protection, particularly for stroke prevention. For secondary stroke prevention, the evidence of intensive BP lowering benefit is limited since only a single RCT for patients with lacunar infarctions was conducted and most data were driven by exploratory analyses. In acute intracerebral hemorrhage, immediate BP lowering targeting systolic $\mathrm{BP}<140 \mathrm{~mm} \mathrm{Hg}$ is recommended by guidelines based on the results from RCTs. In contrast, in acute ischemic stroke, early BP lowering is not usually recommended because of no benefit on functional outcome and future vascular events and potential harm of stroke progression. This review aims to summarize the updated evidence for optimal BP management for primary and secondary stroke prevention and in patients with acute stroke.

\author{
Correspondence: Keun-Sik Hong \\ Department of Neurology, Ilsan Paik \\ Hospital, Inje University, 170 Juhwa- \\ ro, Ilsanseo-gu, Goyang 10380, Korea \\ Tel: +82-31-910-7680 \\ Fax: +82-31-910-7368 \\ E-mail:nrhks@paik.ac.kr \\ Received: January 24, 2017 \\ Revised: April 19, 2017 \\ Accepted: May 2, 2017 \\ Dr. Keun-Sik Hong has received lecture \\ honoraria from Daiichi-Sankyo Korea, \\ Pfizer Korea, Boehringer Ingelheim \\ Korea, Boryung Pharm, and Hanmi \\ Pharm related to the current topic. \\ The author has no financial conflicts of \\ interest.
}

Keywords Blood pressure; Stroke; Prevention, Acute ischemic stroke; Intracerebral hemorrhage

\section{Introduction}

Worldwide, more than one billion people have elevated blood pressure (BP), ${ }^{1}$ and elevated BP is the leading modifiable risk factor for stroke. ${ }^{2}$ The association of high BP and stroke risk is well demonstrated by large epidemiological studies, and the BP lowering benefit on the stroke risk reduction is clearly confirmed by well-designed randomized controlled trials (RCTs). Since the incidence and mortality of stroke as well as major cardiovascular events increase with increasing BP levels beyond $115 / 75 \mathrm{~mm} \mathrm{Hg}_{1}{ }^{3-5}$ the optimal BP in general population is defined as $<120 / 80 \mathrm{~mm} \mathrm{Hg}$. However, for individuals with elevated $B P$, the target for $B P$ lowering, intensive versus less intensive lowering, has long been debated. The uncertainty of target BP for secondary stroke prevention is even greater.

Among patients with acute stroke, BP is elevated in $70-75 \%$ of the patients. Underlying hypertension and physiological or pathological responses to acute stroke likely contribute to the BP elevation. However, the optimal BP management during the acute stage still remains unclear, particularly in patients with acute ischemic stroke.

The last decades have seen accumulated evidences of BP management and stroke. This narrative review will present and discuss the findings from major epidemiological studies and RCTs, focusing on BP management for primary and secondary stroke prevention and patients with acute stroke.

\section{BP Control for Primary Stroke Prevention}

\section{Epidemiological studies}

Multiple epidemiological studies showed that high BP was as- 
sociated with an increased risk of stroke mortality. A large collaborative meta-analysis of individual participant data from 61 prospective observational studies (958,074 individuals with 12.7 million person-years follow-up; 56,335 vascular deaths including 11,960 stroke deaths, 34,283 ischemic heart disease deaths, and 10,092 other vascular deaths) showed that, for $\mathrm{BP} \geq 115 / 75$ $\mathrm{mm} \mathrm{Hg}$, the risk of stroke mortality in all age groups significantly increased with increasing BP levels, and the association of BP was greater with stroke mortality than with ischemic heart disease mortality. In individuals aged 40-69 years, every $20 \mathrm{~mm}$ $\mathrm{Hg}$ decrease in systolic BP (SBP) or $10 \mathrm{~mm} \mathrm{Hg}$ decrease in diastolic BP (DBP) was associated with more than 2-fold decrease in the stroke mortality. ${ }^{3}$

High BP is associated with an increased risk of stroke incidence as well as stroke mortality. The Asia Pacific Cohort Studies Collaboration study including 58 cohort studies (more than 3 million person-year follow-up and 5,178 stroke incidental cases) showed that the risk of stroke incidence increased with increasing BP levels in a dose-dependent manner from the SBP level of $115 \mathrm{~mm} \mathrm{Hg}$. For every $10 \mathrm{~mm} \mathrm{Hg}$ decrease in SBP, the expected risk reduction of stroke incidence was 54\% (95\% confidence interval $[\mathrm{Cl}] 53-56 \%), 36 \%$ (34-38\%) and 25\% (22$28 \%$ ) in individuals with age $<60,60-69$, and $\geq 70$ years, respectively. For both men and women and for both ischemic and hemorrhagic strokes, the risk increased with increasing BP levels. ${ }^{4}$ For North American and European populations, an earlier meta-analysis already demonstrated the association of high BP and stroke incidence. Within the range of DBP $70-110 \mathrm{~mm} \mathrm{Hg}$, DBP reduction of $5 \mathrm{~mm} \mathrm{Hg}, 7.5 \mathrm{~mm} \mathrm{Hg}$, and $10 \mathrm{~mm} \mathrm{Hg}$ was associated with $34 \%, 46 \%$, and $56 \%$ reduction of stroke risk. ${ }^{5}$

In the updated INTERSTROKE phase 2 study with a large standardized case-control set of 26,919 individuals from 32 countries worldwide showing that 10 modifiable risk factors collectively accounted for about $90 \%$ of population-attributable risk for all stroke, hypertension defined as self-reported hypertension or $\mathrm{BP} \geq 140 / 90 \mathrm{~mm} \mathrm{Hg}$ had the largest population-attributable risk of $47.9 \%(99 \% \mathrm{Cl} 45.1-50.6)$. The population-attributable risk was 45.7\% (42.4-49.0) for ischemic stroke and $56.4 \%$ (52.0-60.6) for intracerebral hemorrhage (ICH). The contribution of hypertension to regional stroke burden was greater in Asian region than in Europe, North America, and Australia. ${ }^{2}$

Population-based studies conducted in developed countries suggested that BP control contributes to the reduction of stroke incidence and mortality. In a Unite Kingdom study, between 1981 and 2004, first ever stroke fell by $29 \%$ (relative risk [RR] $0.71,95 \% \mathrm{Cl} 0.61-0.83)$, ischemic stroke by $27 \%(0.73,0.62-$ $0.86)$, and primary ICH by $53 \%(0.47,0.27-0.83)$, which was likely attributed to the improvement in risk factor control and antiplatelet use. Mean BP decreased from 156.3/88.0 mm Hg to $147.6 / 82.0 \mathrm{~mm} \mathrm{Hg}$, and the proportion of taking antihypertensive agents increased from $19.8 \%$ to $47.3 \%{ }^{6}$

The Framingham Study of the United States (US) also showed that, over the periods of 1950-1977, 1978-1989, and 19902004, the age-adjusted incidence of first-ever stroke fell by $25 \%$ (RR $0.75,95 \% \mathrm{Cl} 0.59-0.95)$ in men and 24\% $(0.76,0.61-$ $0.94)$ in women. During the study period, risk factor profiles except for diabetes significantly improved, which likely accounted for the decline in the stroke incidence. From 1950-1977 to 1990-2004, the proportion of individuals with BP>140/90 mm $\mathrm{Hg}$ decreased from $48 \%$ to $34 \%$ in men and from $56 \%$ to $30 \%$ in women, and the proportion of taking antihypertensive agents increased from $11 \%$ to $37 \%$ in men and from $19 \%$ to $27 \%$ in women. ' In the US, stroke mortality has also declined since the early 20th century, resulting in repositioning stroke from the third to the fourth leading cause of death. The National Health and Nutrition Examination Survey data indicated a reduction of SBP in US population (mean SBP, $131 \mathrm{~mm} \mathrm{Hg}$ in 1960-1962 and $122 \mathrm{~mm} \mathrm{Hg}$ in 2001-2008), which might explain the decline in the stroke mortality. ${ }^{8}$

Among Asian studies, the Hisayama study in Japan showed a substantial decline in stroke incidence. The age-adjusted incidence for ischemic stroke significantly declined by $37 \%$ for men and by $32 \%$ for women from the first cohort (enrolled in 1961) to the second cohort (enrolled in 1974), and 29\% for men and $14 \%$ for women from the second cohort to the third cohort (enrolled in 1988). The age-adjusted incidence of ICH also declined in men and women, particularly with a huge reduction of $61 \%$ from the first cohort to the second cohort in men. During the period, the prevalence of severe hypertension defined as $B P \geq 160 / 100 \mathrm{~mm} \mathrm{Hg}$ significantly decreased from $19.1 \%$ to $11.2 \%$ in men and from $17.9 \%$ to $12.0 \%$ in women along with increasing use of antihypertensive agents from $2.1 \%$ to $14.3 \%$ in men and $2.2 \%$ to $15.3 \%$ in women. ${ }^{9}$

In 2014, the Eighth Joint National Committee (JNC8) published an updated guideline recommending a relaxed SBP goal of $<150 \mathrm{~mm} \mathrm{Hg}$ for individuals aged $\geq 60{ }_{1}^{10}$ which elaborated substantial debates among experts and relevant academic societies. In a recent study of individuals aged $\geq 60$ of the Northern Manhattan Study cohort with a 13-year follow-up, individuals with SBP 140-149 mm Hg compared to those with SBP $<140$ $\mathrm{mm} \mathrm{Hg}$ had an increased risk of stroke (hazard ratio [HR] 1.72, $95 \% \mathrm{Cl} 1.20-2.65)$, adding concern on the JNC8 recommendation. ${ }^{11}$

\section{RCTs}

RCTs clearly confirmed the benefit of BP lowering expected 
from epidemiological studies. The majority of individuals enrolled in RCTs were non-stroke population, and the evidences from most RCTs would be more relevant to primary stroke prevention than secondary stroke prevention. Accordingly, large meta-analyses to explore pooled estimates of BP lowering benefit have been conducted and updated.

Pooling 42 RCTs (23 RCTs for stroke endpoint), antihypertensive therapy versus placebo reduced the risk of stroke by $32 \%$ (95\% Cl 24-39). The benefit of stroke risk reduction was greater than those of coronary or major cardiovascular event risk reduction. ${ }^{12}$ In another meta-analysis including 147 RCTs (72 RCTs for stroke endpoint), the RR with the standardized BP lowering of $10 / 5 \mathrm{~mm} \mathrm{Hg}$ was 0.59 (95\% $\mathrm{Cl} 0.52-0.67)$ for stroke endpoint and $0.78(0.73-0.83)$ for coronary heart disease endpoint. ${ }^{13}$

In a recent updated meta-analysis of 123 RCTs (53 RCTs for stroke endpoint), the RR with every $10 \mathrm{~mm} \mathrm{Hg}$ reduction in SBP was $0.73(95 \% \mathrm{Cl}, 0.68-0.77)$, which was smaller than observed in the earlier meta-analysis. However, this updated meta-analysis showed that the benefit of BP lowering for stroke prevention was consistent across diverse baseline SBP levels ( $P$ for trend=0.38), suggesting no J-curve relationship with BP level and stroke risk. In particular, $10 \mathrm{~mm} \mathrm{Hg}$ reduction in SBP was associated with a significant stroke risk reduction in individuals with baseline SBP 130-139 mm Hg (RR 0.73, 95\% Cl 0.620.85), $140-149 \mathrm{~mm} \mathrm{Hg}(0.78,0.70-0.87), 150-159 \mathrm{~mm} \mathrm{Hg}$ $(0.65,0.54-0.78)$, and $\geq 160 \mathrm{~mm} \mathrm{Hg}(0.70,0.64-0.78)$. The benefit of SBP $10 \mathrm{~mm} \mathrm{Hg}$ reduction on stroke risk was comparable between individuals with established cardiovascular disease $(0.74,0.67-0.81)$ and those without established cardiovascular disease $(0.75,0.63-0.89) .^{14}$

\section{Class effect}

Of the modern antihypertensive agents, chlorothiazide was introduced to clinical practice in late 1950s, and then beta-blockers (BBs) in early 1960s, calcium channel blockers (CCBs) and angiotensin converting-enzyme inhibitors in 1970s, and angiotensin receptor blockers (ARBs) in 1990s. Earlier RCTs demonstrated the benefit of diuretics and BBs over placebo for preventing cardiovascular disease. Since then, which antihypertensive agent or combination would be more protective for stroke prevention has been of interest.

Looking at individual large RTCs reporting stroke endpoint, earlier large RCTs showed that CCBs or angiotensin convertingenzyme inhibitors were not superior to diuretics or BBs. ${ }^{15-17}$ In Nordic Diltiazem (NORDIL) study, diltiazem compared to diuretics or BB had a lower risk of stroke (RR, $0.80 ; 95 \% \mathrm{Cl}, 0.65-$ 0.99) only after adjusting for covariates. ${ }^{18}$ However, Losartan Intervention For Endpoint reduction (LIFE) showed that losartan compared to atenolol had a lower risk of stroke (HR 0.75, 95\% Cl 0.63-0.89). ${ }^{19}$ Anglo-Scandinavian Cardiac Outcomes Trial (ASCOT) showed that amlodipine-based BP lowering was better than atenolol-based BP lowering for stroke endpoint (HR 0.77, 0.66-0.89). ${ }^{20}$ In Antihypertensive and Lipid-Lowering treatment to prevent Heart Attack Trial (ALLHAT), chlorthalidone had a lower risk of stroke compared to doxazosin (RR 0.84, 0.71-0.99) and lisinopril $(0.87,0.77-0.98)$, and amlodipine compare to lisinopril had a lower risk of stroke (odds ratio [OR] 0.82, 95\% Cl $0.71-0.94){ }^{21,22}$ However, in these trials designed to compare different antihypertensive classes, other antihypertensive agents were often required for BP control, which might confound the effects of the tested antihypertensive gents.

For patients with $\mathrm{BP}>160 / 100 \mathrm{~mm} \mathrm{Hg}$, combination of antihypertensive agents as an initial therapy is recommended, and many of hypertensive patients require 2 or more anti-hypertensive agents for achieving target BP level. Therefore, the optimal combination therapy is of great interest. In Avoiding Cardiovascular Events through Combination Therapy in Patients Living with Systolic Hypertension (ACCOMPLISH) that enrolled 11,506 patients with $\mathrm{SBP} \geq 160 \mathrm{~mm} \mathrm{Hg}$ or on antihypertensive agents and at high risk for cardiovascular disease, benazepril plus amlodipine compared to benazepril plus hydrochlorothiazide reduced the primary endpoint of the composite of major cardiovascular events (HR 0.80, 95\% Cl 0.72-0.90). Stroke endpoint occurred less frequently with benazepril plus amlodipine, but the difference was not significant $(0.84,0.65-1.08) .{ }^{23}$ In another Japanese trial enrolling 3,501 patients, the stroke risk with benidipine plus thiazide was lower compared to benedipine plus BB (HR 0.43, 95\% Cl 0.22-0.85), but did not differ when compared to benedipine plus ARB $(0.72,0.34-1.45) .^{24}$

An earlier network meta-analysis published in 2003 showed that diuretics were better than angiotensin converting-enzyme inhibitors and similar to CCBs for stroke endpoint. Since other cardiovascular endpoints generally favored diuretics over other antihypertensive classes, this meta-analysis suggested diuretics as a first-line antihypertensive agent, taking into account the overall benefit and cost. ${ }^{12}$ However, in a subsequent meta-analysis, compared to other antihypertensive classes, CCBs were more effective and BBs were less effective for stroke prevention even after adjusting BP reduction difference between comparative agents. ${ }^{13}$ In a recent meta-analysis published in 2016, compared to the other classes, CCBs and ARBs were superior, but angiotensin converting-enzyme inhibitors and $B B s$ were inferior for stroke risk reduction. However, CCBs compared to the other antihypertensive classes were less favorable for heart failure outcome. Of note, these findings were derived from non-standardized analyses without accounting for BP lowering intensity 
and other factors. ${ }^{14}$

Pleiotropic effect, BP variability, and central BP have been proposed to explain the different effect on stroke outcome between antihypertensive classes. However, it should be noted that, in all RCTs comparing different antihypertensive strategies, stroke endpoint was not a primary endpoint, but one of secondary endpoints. Thereby, the positive findings should be interpreted cautiously. Study-level meta-analyses without individual patient data have additional limitations of 1) confounding of achieved BP levels, which influences the study results, and 2) bias from indirect comparison. Therefore, the available evidence from individual RTCs and meta-analyses regarding the differential effects of antihypertensive classes on stroke risk is only suggestive, but not confirmative.

\section{BP Control for Secondary Stroke Prevention}

About $70 \%$ of stroke patients have hypertension. ${ }^{25-28}$ In contrast to primary stroke prevention, there is no large epidemiological study that evaluates whether high BP is associated with an increased risk of recurrent stroke. However, secondary stroke prevention RCTs and their meta-analyses confirmed that BP lowering reduced the risk of recurrent stroke as well as subsequent major cardiovascular events. In addition, post hoc analyses of RCTs testing interventions other than BP lowering showed that high BP during follow-up was associated with an increased risk of recurrent stroke.

\section{RCTs testing BP lowering effect}

The first formal RCT testing BP control to prevent subsequent clinical events in stroke patients was conducted in 1960s. The trial enrolled only 99 hypertensive patients with stroke presumed of ischemic origin and randomized to no BP lowering or BP lowering with methyldopa, bethanidine, debrisoquinine, or thiazide diuretics combined with lifestyle modification of salt intake restriction and weight reduction. The target $\mathrm{BP}$ was $\mathrm{SBP}<160 \mathrm{~mm} \mathrm{Hg}$ and DBP 90-100 $\mathrm{mm} \mathrm{Hg}$. Despite of the small sample size, during the follow-up of 2 to 5 years, the BP lowering group compared to the non-BP lowering group had a lower mortality ( $26 \%$ vs. $46 \%$; $P=0.05$ ), and the mortality reduction was greater in patients who achieved well-controlled BP levels. The BP control group versus the non-BP control group had a lower rate of recurrence of major stroke (20\% vs. $44 \%)$. ${ }^{29} \mathrm{How}$ ever, three subsequent RCTs with small to moderate sample sizes (ranging between 452 and 1,473 patients) failed to demonstrate the benefit of BP lowering (deserpine plus methyclothiazide in one RCT and atenolol in two RCTs) for preventing recur- rent stroke or major cardiovascular events. ${ }^{30-32}$

The first large RCT was Post-stroke Antihypertensive Treatment Study (PATS), which randomized 5,665 Chinese patients with stroke or transient ischemic attack (TIA) (ischemic stroke/ TIA 84\% and hemorrhagic stroke 16\%) to indapamide $2.5 \mathrm{mg}$ or placebo. ${ }^{33,34}$ During a median 2-year follow-up, indapamide (BP lowering of $6.8 / 3.3 \mathrm{~mm} \mathrm{Hg}$ compared to placebo) significantly reduced recurrent stroke by $30 \%$ (HR 0.70, 95\% $\mathrm{Cl} 0.57-0.86$ ) and major cardiovascular events by $25 \%(0.75,0.62-0.89)$.

A subsequent large RCT, Perindopril Protection Against Recurrent Stroke Study (PROGRESS), demonstrated the benefit of BP lowering for secondary stroke prevention. ${ }^{35}$ PROGRESS randomized 6,105 patients with a history of TIA or stroke (ischemic stroke/TIA $84 \%$, hemorrhagic stroke $11 \%$, and undetermined stroke $5 \%$ ) to perindopril-based BP lowering or to placebo. During the 4-year follow-up, the BP difference between the two groups was $9 / 4 \mathrm{~mm} \mathrm{Hg}$, and BP lowering reduced the primary end point of recurrent stroke by $28 \%(95 \% \mathrm{Cl} 17-38 \%)$ and major cardiovascular events by 26\% (16-34\%). The magnitude of benefit for preventing recurrent stroke was similar to that observed in PATS.

In a meta-analysis involving 15,527 patients from 7 RCTs published until 2002 (6 RCTs exclusively enrolling stroke/TIA patients and one RCT with prior stroke/TIA subgroup), BP lowering with antihypertensive agents reduced stroke (OR $0.76,95 \% \mathrm{Cl}$ 0.63-0.92), nonfatal stroke $(0.79,0.65-0.95)$, myocardial infarction $(0.79,0.63-0.98)$, and overall vascular events $(0.79,0.66-$ $0.95)^{36}$

After then, Prevention Regimen For Effectively avoiding Second Strokes (PRoFESS), the largest secondary stroke prevention RCT with a sample size of 20,332, compared telmisartan versus placebo on top of background antihypertensive treatment as needed. For 2.5 years, telmisartan did not significantly reduce recurrent stroke (HR 0.95, 95\% $\mathrm{Cl} 0.86-1.04$ ) or the composite of recurrent stroke, myocardial infarction, new or worsening heart failure, or vascular death $(0.94,0.87-1.01)$. However, by the end of the trial, the placebo group compared to the telmisartan group more frequently took other antihypertensive agents, and the mean BP difference was only $3.8 / 2.0 \mathrm{~mm} \mathrm{Hg}$. In post hoc analyses, the clinical event rates did not differ in the first 6 months $(1.07,0.92-1.25)$, but lowered with telmisartan after 6 months $(0.88,0.78-0.99)$, suggesting that more prolonged treatment with telmisartan could have resulted in a significant benefit. $^{37}$

In an updated meta-analysis involving 38,421 patients from 10 RCTs published until 2009 (7 RCTs exclusively enrolling stroke/TIA patients and 3 RCTs with prior stroke/TIA subgroup), antihypertensive therapy reduced stroke $(\mathrm{OR}, 0.78,95 \% \mathrm{Cl}$ 
0.68-0.90). ${ }^{34}$ In another meta-analysis of 11 placebo-controlled RCTs published until July 2016, antihypertensive therapy reduced recurrent stroke (RR $0.73,95 \% \mathrm{Cl} 0.62-0.87$ ), disabling or fatal stroke $(0.71,0.59-0.85)$ and vascular death $(0.85,0.75-$ 0.96). ${ }^{38}$

\section{Post hoc analyses of RCTs testing intervention other than BP lowering}

In a post hoc analysis of the Vitamin Intervention for Stroke Prevention (VISP) trial which enrolled patients with recent stroke, patients with mean follow-up $\mathrm{BP}<140 / 90 \mathrm{~mm} \mathrm{Hg}$ versus those with $B P \geq 140 / 90 \mathrm{~mm} \mathrm{Hg}$ had lower risks of recurrent stroke (HR 0.76, 95\% Cl 0.59-0.98) and major cardiovascular events $(0.76,0.62-0.92)$. Of note, among patients with baseline SBP in the highest quartile ( $>153 \mathrm{~mm} \mathrm{Hg})$, patients with $\mathrm{BP}$ controlled $\geq 75 \%$ of the trial period compared to those with $\mathrm{BP}$ controlled $<25 \%$ had a lower risk of stroke $(0.46,0.26-0.84)$, and major cardiovascular events $(0.51,0.32-0.82) .^{39}$

In a post hoc analysis of PRoFESS, compared to patients with mean follow-up SBP 130-139 mm Hg, the SBP 140-149 mm $\mathrm{Hg}$ group had a higher risk of recurrent stroke (adjusted HR, $1.23,95 \% \mathrm{Cl} 1.07-1.41)$ and major cardiovascular events (1.24, 1.11-1.39). The risk was further increased in the $S B P \geq 150 \mathrm{~mm}$ Hg group; 2.08 (1.83-2.37) for recurrent stroke and 1.94 (1.742.16) for major cardiovascular events. ${ }^{40}$

Patients with symptomatic extracranial or intracranial stenosis might have impaired regional cerebral perfusion, and thereby some advocate maintaining high BP in these patients. However, data have suggested that high BP is associated with a higher risk of recurrent stroke, even in the territory of symptomatic stenosis.

For symptomatic extracranial carotid stenosis, a pooled analysis of individual patient data from the European Carotid Surgery Trial (ECST) and North American Symptomatic Carotid Endarterectomy Trial (NASCET) studies showed that high BP was associated with an increased risk of recurrent stroke in patients assigned to medical treatment. The presence of contralateral asymptomatic occlusion did not change the relationship between BP level and stroke risk. Only in patients with bilateral stenoses $\geq 70 \%$, the relationship was reversed (higher stroke risk with lower BP). In patients with unilateral stenosis $\geq 70 \%$, there was a positive relationship between BP level and stroke risk. The findings from this post hoc analysis support BP lowering in the majority of patients with symptomatic carotid stenosis except for bilateral severe stenosis. ${ }^{41}$

For symptomatic intracranial stenosis, uncontrolled BP is likely to increase the risk of subsequent vascular events. In a post hoc analysis of Warfarin-Aspirin Symptomatic Intracranial Dis- ease (WASID) trial, compared to patients with mean $\mathrm{SBP}<140$ $\mathrm{mm} \mathrm{Hg}$ during the trial, those with mean SBP $>140 \mathrm{~mm} \mathrm{Hg}$ had an increased risk of recurrent stroke (adjusted $\mathrm{HR}, 1.63,95 \% \mathrm{Cl}$ 1.11-2.40) and major cardiovascular events (1.79, 1.27-2.52). Based on the WASID data, the Stenting and Aggressive Medical Management for Prevention of Recurrent Stroke in Intracranial Stenosis (SAMMPRIS) investigators targeted SBP $<140 \mathrm{~mm}$ $\mathrm{Hg}^{42,43}$ Data from the medical arm in SAMMPRIS showed that the risk of the composite of stroke, myocardial infarction, or vascular death at 3 years was higher with follow-up SBP $>140$ $\mathrm{mm} \mathrm{Hg}$ vs. $\mathrm{SBP} \leq 140 \mathrm{~mm} \mathrm{Hg}$ (unadjusted $\mathrm{OR} 2.1,95 \% \mathrm{Cl} 1.2-$ 4.0), ${ }^{44}$ but the risk of recurrent ischemic stroke did not increase in patients with mean follow-up $\mathrm{SBP} \geq 144 \mathrm{~mm} \mathrm{Hg}$ vs. $\mathrm{SBP}<144$ $\mathrm{mm} \mathrm{Hg}$ (unadjusted HR 0.6, 95\% Cl 0.3-1.2). ${ }^{45}$ However, results from adjusted analyses are not available.

\section{Intensive vs. Less Intensive BP Lowering for Stroke Prevention}

\section{Evidences from non-stroke population in majority} As previously described, large meta-analyses of epidemiological studies showed that the association of BP and the stroke incidence as well as stroke mortality is continuous down to $115 / 75$ $\mathrm{mm} \mathrm{Hg}$, suggesting "the lower, the better." The expected benefit was consistent across a wide range of subgroups. ${ }^{3-5}$

In post hoc analyses of two large RCTs testing BP lowering therapy (International Verapamil-Trandolapril Study [INVEST] that enrolled patients with coronary heart disease; Ongoing Telmisartan Alone and in combination with Ramipril Global Endpoint Trial [ONTARGET] that enrolled patients with established cardiovascular disease or diabetes plus end-organ disease), there were J-curve relationships between follow-up BP level and major cardiovascular events or coronary event. However, the risk of stroke increased with increasing follow-up BP level, indicating no J-curve phenomenon for the BP and stroke risk relationship. ${ }^{46,47}$

Action to Control Cardiovascular Risk in Diabetes (ACCORD) was a pivotal large RCT that specifically compared intensive $(\mathrm{SBP}<120 \mathrm{~mm} \mathrm{Hg}$ ) versus conventional (SBP $<140 \mathrm{~mm} \mathrm{Hg})$ BP lowering in patients with type 2 diabetes and at high risk for major cardiovascular events. Intensive BP lowering compared to conventional BP lowering did not reduce the primary endpoint of major cardiovascular events. However, among prespecified secondary endpoints, the stroke endpoint was significantly reduced with intensive BP lowering (HR 0.59, 95\% Cl 0.39$0.89) .^{48}$ In a subsequent meta-analysis of 13 RCTs involving 37,736 patients with type 2 diabetes or impaired fasting glucose, intensive SBP control ( $\leq 135$ or $130 \mathrm{~mm} \mathrm{Hg}$ ) versus less in- 
tensive SPB control was associated with a lower risk of stroke (OR $0.83,95 \% \mathrm{Cl} 0.73-0.95)$ as well as all-cause death (0.90, $0.83-0.98)$, but with an increased risk of serious adverse events (1.20, 1.08-1.32). With more intensive SBP lowering of $<130$ $\mathrm{mm} \mathrm{Hg}$, the stroke risk was further reduced $(0.53,0.38-0.75)$, but the risk of serious adverse events also increased $(1.40,1.19-$ 1.64). ${ }^{49}$

For Asian data, the investigators of China Stroke Primary Prevention Trial (CSPPT), which tested the effect of folate on primary stroke prevention, conducted a post-hoc analysis exploring the relationship between the average follow-up SBP level and the risk of first stroke. The stroke risk was lowest in patients with the average SBP level of 120-130 $\mathrm{mm} \mathrm{Hg}$, and the risk increased in those with $\mathrm{SBP}<120 \mathrm{~mm} \mathrm{Hg}(\mathrm{HR} 4.37,95 \% \mathrm{Cl} 2.10-$ 9.07) as well as those with SBP $130-135 \mathrm{~mm} \mathrm{Hg}(1.63,1.01-$ 2.63), $135-140 \mathrm{~mm} \mathrm{Hg}(1.85,1.17-2.93)$, and $>140 \mathrm{~mm} \mathrm{Hg}$ $(3.83,2.54-5.76)$, indicating a J-curve relationship. However, for $\mathrm{DBP}$, patients with $\mathrm{DBP}<80 \mathrm{~mm} \mathrm{Hg}$ had the lowest stroke risk, compared to those with DBP $80-90 \mathrm{~mm} \mathrm{Hg}(2.14,1.65-2.77)$ and $\mathrm{DBP}>90 \mathrm{~mm} \mathrm{Hg}(5.55,4.04-7.62)$. Similar findings were also observed for the endpoint of ischemic stroke. ${ }^{50}$

In an earlier meta-analysis of 11 studies involving 42,572 patients, achieving SBP $<130 \mathrm{~mm} \mathrm{Hg}$ compared to SBP 130-139 $\mathrm{mm} \mathrm{Hg}$ was associated with a lower risk of stroke (RR 0.80, $95 \% \mathrm{Cl} 0.70-0.92)$ and major cardiovascular events $(0.91,0.86-$ 0.96). However, the benefit of achieving $\mathrm{SBP}<130 \mathrm{~mm} \mathrm{Hg}$ was heterogeneous ( $P$ for heterogeneity $=0.002$ ) between subjects with established cardiovascular disease $(0.88,0.76-1.03)$ and those without established cardiovascular disease $(0.49,0.34-$ 0.69). Reported hypotension was more common with intensive lowering ( $1.4 \%$ vs. $0.4 \%$, RR $3.43,95 \% \mathrm{Cl} 2.46-4.79) .{ }^{51} \mathrm{An}$ updated meta-analysis of 19 trials $(n=44,989)$ also demonstrated similar findings; intensive BP lowering (mean BP, 133/76 mm $\mathrm{Hg}$ ) versus less intensive $B P$ lowering (mean $B P, 140 / 81 \mathrm{~mm} \mathrm{Hg}$ ) was associated with a lower risk of stroke (RR $0.78,95 \% \mathrm{Cl}$ $0.68-0.90)$ and major cardiovascular events $(0.86,0.78-0.96)$. In this meta-analysis, the reduction of major vascular events with intensive BP lowering was consistent across a wide range of subgroups. Serious adverse events was not significantly increased with intensive BP lowering (1.2\% vs. $0.9 \%$, RR 1.35 , $95 \% \mathrm{Cl} 0.93-1.97)$. Severe hypotension was more common with intensive lowering $(2.68,1.21-5.89)$, but the absolute increase was not substantial (0.3\%/year vs. $0.1 \% /$ year) ${ }^{52}$

The Systolic Blood Pressure Intervention Trial (SPRINT) was the first large trial that confirmed the benefit of intensive BP lowering over less intensive BP lowering. SPRINT compared SBP target $<120 \mathrm{~mm} \mathrm{Hg}$ vs. $<140 \mathrm{~mm} \mathrm{Hg}$ in individuals with $\mathrm{SBP} \geq 130 \mathrm{~mm} \mathrm{Hg}$ and at high risk of cardiovascular disease. Pa- tients with diabetes, stroke, or congestive heart failure were excluded. It was early terminated because of a clear benefit of intensive BP lowering after a median follow-up of 3.26 years. The intensive BP lowering significantly reduced the primary endpoint of major cardiovascular events (HR 0.75, 0.64-0.89). The benefit on the primary endpoint was consistent across prespecified subgroups regarding age ( $<75$ years vs. $\geq 75$ years), sex, race, established cardiovascular disease, chronic kidney disease, and baseline SBP levels. In addition, intensive BP lowering significantly reduced all-cause death $(0.73,0.60-0.90)$ and cardiovascular death $(0.57,0.38-0.85)$. Serious adverse events of hypotension, syncope, electrolyte abnormalities, and acute kidney injury or failure were more common in the intensive BP lowering group, but there was no difference in the overall serious adverse event rate. ${ }^{53}$ Therefore, the target $\mathrm{BP}<140 / 90 \mathrm{~mm} \mathrm{Hg}$ in individuals aged $<60$ and $<150 / 90 \mathrm{~mm} \mathrm{Hg}$ in those aged $\geq 60$ recommended by the Eighth Joint National Committee Guidelines should be reconsidered. ${ }^{10}$ Unexpectedly, there was no significant stroke risk reduction with intensive BP lowering $(0.89$, 0.63-1.25). ${ }^{53}$ However, if the ACCORD and SPRINT data combined, target $\mathrm{SBP}<120 \mathrm{~mm} \mathrm{Hg}$ vs. $<140 \mathrm{~mm} \mathrm{Hg}$ was associated with a reduction in stroke risk $(0.75,0.58-0.97) .{ }^{54}$ The magnitude of stroke risk benefit was largely in accord with the findings estimated by the earlier meta-analyses. ${ }^{51,52}$

In contrast, for individuals at intermediate risk who did not have established cardiovascular disease, the Heart Outcomes Prevention Evaluation (HOPE)-3 trial showed that active BP lowering with candesartan plus hydrochlorothiazide did not reduce the risk of stroke (HR $0.80,95 \% \mathrm{Cl}$ 0.59-1.08) as well as the primary endpoint of major cardiovascular events $(0.93,0.79-1.10)$. However, dizziness, lightheadedness, or symptomatic hypotension leading to permanent study medication discontinuation was more common with antihypertensive therapy ( $3.4 \%$ vs. $2.0 \%, P<0.0001)$. Compared to the ACCORD and SPRINT populations, the HOPE-3 population was at intermediate risk, reflected by the much lower rate of major cardiovascular events compared to those in the ACCORD and SPRINT trials. Of the prespecified subgroups based on follow-up mean SBP levels, only the participants in the highest tertile group (mean $\mathrm{SBP}>143.5 \mathrm{~mm} \mathrm{Hg}$ ) benefited from antihypertensive therapy for stroke endpoint $(0.58,0.37-0.90)$ and the primary endpoint $(0.73,0.56-0.94)$. Therefore, the findings suggest that, in individuals without high risk, antihypertensive therapy would be beneficial only for SBP>140 mm Hg. Of note, the effect of antihypertensive therapy on the primary endpoint differ significantly according to mean SBP levels (antihypertensive therapy effect; better in the highest tertile, 
neutral in the intermediate tertile, and worse in the lowest tertile; $P$ for trend $=0.02$ ), suggesting a J-curve phenomenon. In contrast, the effect of antihypertensive therapy on stroke endpoint showed no significant interaction with the mean SBP levels, supporting no J-curve relationship. ${ }^{55}$

\section{Evidences from stroke population}

Several post hoc analyses of RCTs data have explored whether intensive BP lowering would further reduce the risk of recurrent stroke in stroke patients. In a post-hoc analysis of PROGRESS, there was no J-curve relationship between follow-up BP levels and the risk of recurrent stroke. When patients were categorized into 4 groups according to their follow-up SBP levels $(<120,120-139,140-159$, and $\geq 160 \mathrm{~mm} \mathrm{Hg})$, the lowest SBP group had the lowest risk of recurrent stroke, and the risk monotonically and significantly increased with increasing follow-up SBP level $(P$ for trend $<0.0001$ ). The relationship was also significant for both ischemic and hemorrhagic stroke risks, and it was stronger for the hemorrhagic stroke risk than the ischemic stroke risk. Lower SBP levels were associated with more frequent minor adverse events, but did not significantly increase serious adverse events. Therefore, this post hoc analysis supports intensive BP lowering for secondary stroke prevention. $^{56}$

In contrast, data from PRoFESS, a more recent and larger trial than PROGRESS, showed a J-curve relationship between followup BP levels and stroke risk as well as major cardiovascular events risk. The risk of recurrent stroke was lowest in patients with follow-up SBP 130-139 mm Hg (as reference), and significantly increased in those with very low-normal $(<120 \mathrm{~mm} \mathrm{Hg}$, HR 1.29, 95\% Cl 1.07-1.56), high (140-149 mm Hg, 1.23, 1.071.41 ), or very high ( $\geq 150 \mathrm{~mm} \mathrm{Hg}, 2.08,1.83-2.37$ ) SBP level. There was a similar relationship between the major cardiovascular events risk and the follow-up SBP level. Therefore, the PRoFESS post hoc analysis supports the conventional BP lowering, targeting $\mathrm{SBP}<140 \mathrm{~mm} \mathrm{Hg}$, rather than intensive BP lowering. ${ }^{40}$

For symptomatic intracranial stenosis, a WASID post hoc analysis $(n=567)$ showed that the recurrent risks of any ischemic stroke and ischemic stroke in the stenotic territory increased with increasing mean follow-up SBP ( $P$ for trend $=0.0008$, and 0.0002 , respectively) and DBP ( $P$ for trend $<0.0001$, and 0.0005 , respectively) levels. However, the increased risks were largely driven by the highest SBP group ( $\mathrm{SBP} \geq 160 \mathrm{~mm} \mathrm{Hg}$ ) (any ischemic stroke, HR 4.6, 95\% Cl, 1.316.2; ischemic stroke in the stenotic territory, 3.9, 1.1-14.1), and these risks did not significantly increased in the mean SBP $120-139 \mathrm{~mm} \mathrm{Hg}$ and $140-159 \mathrm{~mm} \mathrm{Hg}$ groups compared to the mean $\mathrm{SBP}<120 \mathrm{~mm} \mathrm{Hg}$ group. For DBP levels, the risks of any ischemic stroke and ischemic stroke in the stenotic territory had significantly increased in the DBP 80-89 mm Hg ([any ischemic stroke, 2.2, 1.4-3.4]; stroke in the stenotic territory 2.2, 1.3-3.7) and $\mathrm{DBP} \geq 90 \mathrm{~mm} \mathrm{Hg}$ ([any ischemic stroke, HR 4.6, 2.1-10.4]; stroke in the stenotic territory 5.1, 2.1-12.4) compared to the lowest DBP group ( $\mathrm{DBP}<80 \mathrm{~mm} \mathrm{Hg}$ ). In subgroups according to stenosis severity, the relationship between the risk and followup BP levels was more apparent in patients with stenosis $<70 \%$ than in those with stenosis $\geq 70 \%$. The study findings do not strongly support intensive BP lowering in symptomatic intracranial stenosis, but do not support maintaining high BP for cerebral perfusion in patients with in symptomatic intracranial stenosis. In addition, there was no J-shape relationship between BP levels and any ischemic stroke or ischemic stroke in the stenotic territory. ${ }^{57}$

In the Carotid Occlusion Surgery Study (COSS) trial that enrolled patients with symptomatic carotid artery occlusion and hemodynamic cerebral ischemia, the target BP level was $\leq 130 / 85 \mathrm{~mm} \mathrm{Hg}$, a moderately intensive BP lowering target. Among 91 patients assigned to the medical treatment arm, patients achieving BP levels $\leq 130 / 85 \mathrm{~mm} \mathrm{Hg}$ compared to those with $\mathrm{BP}>130 / 85 \mathrm{~mm} \mathrm{Hg}$ had a lower risk of recurrent ipsilateral ischemic stroke (HR 0.27, 95\% Cl 0.08-0.94). In addition, there was no J-curve relationship between the ipsilateral ischemic stroke risk and SBP levels (categorized as $<120,120-129,130-$ 139, 140-149, and $>150 \mathrm{~mm} \mathrm{Hg})^{58}$

However, the Vertebrobasilar Flow Evaluation and Risk of Transient Ischemic Attack and Stroke (VERiTAS) study which enrolled 72 patients with recent vertebrobasilar TIA or stroke and $\geq 50 \%$ of vertebral or basilar arteries showed that the association with BP levels and stroke risk differed by flow status determined by quantitative magnetic resonance angiography. For $20 \pm 8$ months follow-up, the annual rate of the vertebrobasilar artery territory ischemic stroke was highest in patients with low flow and mean follow-up BP<140/90 mm Hg (27.1\%/year, 95\% $\mathrm{Cl}$ 10.2-72.2) followed by those with low flow and mean $\mathrm{BP} \geq 140 / 90 \mathrm{~mm} \mathrm{Hg}$ (9.3\%/year, 1.3-66.0), those with normal flow and mean $\mathrm{BP}<140 / 90 \mathrm{~mm} \mathrm{Hg}$ (6.0\%/year, 1.9-18.5), and those with normal flow and mean $B P \geq 140 / 90 \mathrm{~mm} \mathrm{Hg}$ follow-up (4.8\%/year, 1.2-19.1), suggesting that strict BP control might increase the recurrent stroke risk in patients with reduced distal flow. $^{59}$

Secondary Prevention of Small Subcortical Strokes (SPS3) is the only one RCT that formally compared intensive $(\mathrm{SBP}<130$ $\mathrm{mm} \mathrm{Hg}$ ) versus less intensive (SBP 130-149 mm Hg) BP control in stroke patients. The trial exclusively enrolled patients with ischemic stroke due to small vessel occlusion, who are expected 
to benefit most from intensive BP control. The SPB difference at 1-year after randomization was $11 \mathrm{~mm} \mathrm{Hg}(127 \mathrm{~mm} \mathrm{Hg}$ vs. 138 $\mathrm{mm} \mathrm{Hg}$ ). During a 3.7-year follow up, there was no significant reduction with intensive lowering in the primary endpoint of all recurrent stroke (HR 0.81,95\% $\mathrm{Cl} 0.64-1.03$ ). However, intensive BP control significantly reduced the risk of $\mathrm{ICH}(0.37,0.15-$ 0.95), and did not increase the risk of treatment-related serious adverse events. ${ }^{60}$ Based on the findings from SPS3, the current American Stroke Association guidelines recommend $\mathrm{SBP}<130$ $\mathrm{mm} \mathrm{Hg}$ in patients with stroke due to small vessel occlusion (Class Ilb, Level of Evidence B). ${ }^{61}$

A recent systematic review explored whether the intensive BP lowering might further reduce the recurrent stroke and subsequent major cardiovascular events in stroke patients. Metaregression analysis showed that the intensity of SBP reduction was linearly related to reduced risk of recurrent stroke ( $P=0.049)$, myocardial infarction $(P=0.024)$, all-cause death $(P=0.001)$, and cardiovascular death $(P<0.001)$. When the achieved mean SBP levels were categorized into three groups, patients with mean $\mathrm{SBP}<130 \mathrm{~mm} \mathrm{Hg}$ compared to those with SBP $130-140 \mathrm{~mm} \mathrm{Hg}$ and those with SBP>140 $\mathrm{mm} \mathrm{Hg}$ had a lower risk of recurrent stroke ( $8.3 \%$ vs. $9.2 \%$ vs. $11.7 \%$; $P=0.048)$ and cardiovascular death ( $0.8 \%$ vs. $3.3 \%$ vs. $5.5 \%$; $P=0.049$ ), suggesting a target $\mathrm{SBP}<130 \mathrm{~mm} \mathrm{Hg}$ in stroke patients. ${ }^{38}$

\section{BP Management in Acute Stroke}

In a representative large data set in the US involving 563,704 patients with stroke admitted to ER, initial SBP was 140-184 $\mathrm{mm} \mathrm{Hg}$ in $56 \%$, and $\geq 185 \mathrm{~mm} \mathrm{Hg}$ in $13 \% .{ }^{62}$ In the majority of patients, BP spontaneously falls over the first 7 days after stroke onset. Because cerebral autoregulation is impaired in acute stroke, elevated BP might be beneficial by increasing perfusion in ischemic penumbra area. However, high BP might be harmful by aggravating hematoma expansion or edema in $\mathrm{ICH}$ and symptomatic hemorrhagic transformation or edema in large ischemic stroke. Several RCTs have been conducted to test BP lowering effect in acute stroke.

\section{BP management in acute ischemic stroke}

Data from the International Stroke Trial (IST) showed a Ushaped relationship between SBP measured immediately after randomization and 14-day clinical outcomes. SBP level around $150 \mathrm{~mm} \mathrm{Hg}$ was associated with the lowest risks mortality and poor outcome of death or dependency. High BP was associated with early recurrent stroke and death presumed of cerebral edema, while low BP was associated with early coronary death. $^{63}$

Acute Candesartan Cilexetil Therapy in Stroke Survivors (ACCESS) was a small phase II RCT comparing candesartan (initiated at 30 hours after onset) versus placebo for the first 7 days in patients with acute ischemic stroke. After 7 days, both groups received candesartan if BP control was required. The trial was early terminated after enrolling 342 patients because the candesartan group had a significant lower rate in the composite of vascular events and death at one year (OR 0.48, 95\% Cl 0.250.90). However, the mechanism of candesartan benefit was unclear because the SBP and DBP levels during the trial did not differ between the two groups and the event rates diverged after 2 weeks. In addition, candesartan did not improve the primary endpoint of 3-month disability as measured by Barthel Index. $^{64}$

The Controlling Hypertension and Hypotension Immediately Post-Stroke (CHHIPS) compared active BP lowering (lisinopril or labetalol) versus placebo in 179 patients with acute stroke (57.6\% ischemic stroke, $14.5 \%$ primary $\mathrm{ICH}, 27.9 \%$ undetermined) within 36 hours and SBP>160 mm Hg. SBP decline during the first 24 hours was greater with active BP lowering than placebo ( $21 \mathrm{~mm} \mathrm{Hg}$ vs. $11 \mathrm{~mm} \mathrm{Hg}, P=0.004$ ). There were no differences in the primary endpoint of 14-day death or dependency (modified Rankin Scale [mRS] 4-6), early neurological deterioration, and serious adverse events. However, 3-month mortality showed a trend of favoring active BP lowering $(9.7 \%$ vs. 20.3\%, HR 0.40,95\% Cl 0.2-1.0). However, CHHIPS was a small pilot trial at high risk of type I error. ${ }^{65}$

Because of the uncertainty with the ACCESS results, Scandinavian Candesartan Acute Stroke Trial (SCAST), a large phase III trial, was conducted. SCAST, using a design similar to ACCESS, randomized 2,029 patients with acute stroke (ischemic stroke in $85 \%$, hemorrhagic stroke in 14\%, and TIA or non-stroke in 1\%) and $\mathrm{SBP} \geq 140 \mathrm{~mm} \mathrm{Hg}$ within $30 \mathrm{~h}$ from onset. $\mathrm{BP}$ was lower on day 7 with candesartan (mean difference, $5 / 2 \mathrm{~mm} \mathrm{Hg}$ ), but was similar during the following 6-month between the two groups. The composite endpoint of major cardiovascular events for 6 months did not differ between the candesartan and placebo groups (HR 1.09, 95\% Cl 0.84-1.41). However, the mRS distribution at 6 months showed a worse trend with candesartan treatment (OR 1.17, 95\% Cl 1.00-1.38). Therefore, SCAST suggested a harmful effect with early BP lowering with candesar$\tan ^{66}$

The Valsartan Efficacy oN modesT blood pressUre Reduction in acute ischemic stroke (VENTURE) trial, which enrolled 393 patients with acute ischemic stroke within 48 hours, also showed a harmful effect of early BP lowering. Valsartan treatment versus no antihypertensive treatment for the first 7 days 
did not reduce functional disability and major cardiovascular events at 90 days, but had more early neurological deterioration within 7 days (OR 2.43, 95\% Cl 1.25-4.73). Particularly, in subgroups of patients with large artery atherosclerosis and those with any degree of symptomatic stenosis, early valsartan treatment significantly increased the risk of early neurological deterioration. ${ }^{67}$ SCAST subgroup analysis showed similar findings. In patients with moderate to severe carotid artery stenosis, progressive stroke occurred more frequently in the candesartan group than in the placebo group (11.5\% vs. $4.0 \%)$, and the risk increased with increasing severity of stenosis ( $P$ for trend $=0.04)^{68}$

Another large RCT also showed no benefit of early BP lowering in acute ischemic stroke. The China Antihypertensive Trial in Acute Ischemic Stroke (CATIS) trial enrolled 4,071 patients with acute ischemic stroke within 48 hours and SBP between 140$220 \mathrm{~mm} \mathrm{Hg}$. BP lowering intervention targeted SBP lowering by $10 \%$ to $25 \%$ within the first 24 hours after randomization and $<140 / 90 \mathrm{~mm} \mathrm{Hg}$ within 7 days, while the control group did not receive antihypertensive treatment during hospitalization. SBP difference was significant over the first 14 days; $9.1 \mathrm{~mm} \mathrm{Hg}$ at 24 hours, $9.3 \mathrm{~mm} \mathrm{Hg}$ at day 7, and $8.6 \mathrm{~mm} \mathrm{Hg}$ at 14 days after randomization. The primary outcome of $\mathrm{mRS}$ score 3-6 at 14 days or discharge did not differ between the BP lowering and control arms (33.6\% vs. 33.6\%, OR 1.00, 95\% Cl 0.88-1.14). At 3 months, there were no differences in the mRS score 3-6 (25.2\% vs. $25.3 \%, 1.00,0.88-1.14)$, recurrent stroke (1.4\% vs. $2.2 \%, 0.65,0.40-1.04)$, vascular event $(2.4 \%$ vs. $3.0 \%, 0.81$, $0.55-1.19)$, and death or vascular events ( $4.6 \%$ vs. $4.7 \%, 0.98$, $0.73-1.31)^{69}$

In a meta-analysis of 13 RCTs with 12,703 patients comparing early BP lowering versus control within 3 days of ischemic stroke onset, BP lowering did not reduce the risk of death or dependency (mRS 3-6 or equivalent) at 3 months or at trial end (RR 1.04, 95\% Cl 0.96-1.13). In addition, the effect of early BP lowering was not significant for 3 or 6 -month recurrent stroke $(1.00,0.54-1.84)$, subsequent vascular events $(0.90,0.65-1.25)$, all-cause mortality $(0.99,0.83-1.17)$, and mRS 2-6 outcome $(1.01,0.98-1.04)$. BP lowering was not associated with an increased risk of serious adverse event at 14 or 30 days (1.32, 0.80-2.18). However, limited data did not allow an adequate exploration of the stroke progression risk associated with early BP lowering. ${ }^{70}$

\section{BP management after reperfusion therapy}

In patients treated with intravenous tissue plasminogen activator (IV-TPA), guidelines are recommending $\mathrm{BP}<180 / 105 \mathrm{~mm}$ $\mathrm{Hg} .{ }^{71}$ However, this recommendation is based on expert consen- sus, extrapolating the findings from thrombolysis trials in myocardial infarction, and is largely applicable to BP management in patients with IV-TPA treatment. ${ }^{72,73}$ Currently, the optimal BP management after reperfusion therapy remains unclear.

Data from In the Safe Implementation of Thrombolysis in Stroke (SITS) register showed that baseline high SBP was associated with symptomatic ICH and baseline DBP>90 $\mathrm{mm} \mathrm{Hg}$ was associated with poor outcome. ${ }^{74}$ For BP between 2-24 hours after IV-TPA, the symptomatic ICH risk increased with increment in the average SBP levels, whereas the average SBP level of 141-150 mm Hg was associated with the highest odds of achieving mRS $0-2$ at 3 months. ${ }^{75}$ Therefore, the SITS data suggest that SBP 141-150 mm Hg might be optimal after IV-TPA therapy. Enhanced Control of Hypertension and Thrombolysis Stroke Study (ENCHANTED), which compares SBP 130-140 mm $\mathrm{Hg}$ vs. $\mathrm{SBP}<180 \mathrm{~mm} \mathrm{Hg}$ in patients treated with IV-TPA, is ongoing and may help to resolve the uncertainty. ${ }^{76}$

The optimal BP level after thrombolysis should be differed by recanalization status. In patients with successful recanalization, immediate BP lowering might reduce the risk of symptomatic ICH. In a single center study, the association of BP level in the first 24 hours after reperfusion therapy and functional outcome differed by recanalization status. In patients without recanalization, the relationship between BP level and outcome was U-shaped. In contrast, in patients with early recanalization, the relationship was linear and high BP was associated with worse outcome, possibly due to an increased risk of hemorrhagic transformation or symptomatic $\mathrm{ICH}^{77}$ However, the reperfusion status after IV-TPA treatment is not readily evaluable in clinical practice and even in clinical trial settings.

In contrast to IV-TPA therapy, endovascular recanalization therapy can immediately assess the recanalization status. Patients who achieved successful recanalization are at risk of reperfusion hemorrhage. Since high BP likely increases the risk of symptomatic ICH, aggressive BP control might be warranted. However, the current guidelines recommend a target $\mathrm{BP}<180 / 105$ $\mathrm{mm} \mathrm{Hg}$ in patients treated with IV-TPA, but do not provide a specific recommendation for target BP in those treated with endovascular therapy. Therefore, a relevant RCT is needed to define the optimal BP target after endovascular reperfusion therapy.

\section{$\mathrm{BP}$ management in acute ICH}

Current guidelines recommend lowering $\mathrm{SBP}<140 \mathrm{~mm} \mathrm{Hg}$ within 6 hours of ICH onset, ${ }^{78,79}$ largely based on the Intensive Blood Pressure Reduction in Acute Cerebral Haemorrhage Trial (INTERACT) 2 results. Among earlier pilot RCTs, INTERACT enrolling 404 patients with $\mathrm{ICH}$ within 6 hours showed that early inten- 
sive BP lowering (target SBP $140 \mathrm{~mm} \mathrm{Hg}$ ) vs. SBP $<180 \mathrm{~mm} \mathrm{Hg}$ was safe and might reduce the risk of hematoma expansion. ${ }^{80}$ The Antihypertensive Treatment of Acute Cerebral Haemorrhage (ATACH) trial also showed that acute BP lowering down to SBP $110-140 \mathrm{~mm} \mathrm{Hg}$ with intravenous nicardipine was safe and feasible. ${ }^{81}$

INTERACT2 was a phase III trial enrolling 2,839 patients with ICH within 6 hours. Intensive SBP lowering $<140 \mathrm{~mm} \mathrm{Hg} \mathrm{com-}$ pared to $\mathrm{SBP}<180 \mathrm{~mm} \mathrm{Hg}$ did not significantly reduce the primary endpoint of 90-day mRS 3-6 (52.0\% vs. $55.6 \%$, OR 0.87 , $95 \% \mathrm{Cl} 0.75-1.01)$, but had a favorable shift on the 90-day mRS distribution (OR $0.87,95 \% \mathrm{Cl} 0.77-1.00$ ), which was a prespecified analysis. Between the two groups, the rate of allcause death was comparable $(0.99,0.79-1.25)$, and the contribution of ICH to death was also comaparable. Intenisve BP lowering increased neither neurological deterioration within 24 hours $(0.95,0.77-1.17)$ nor non-fatal serious adverse events (3.4\% vs. $3.8 \%, P=0.92$ ). ${ }^{82}$

ATACH-2 compared SBP target of $110-139 \mathrm{~mm} \mathrm{Hg}$ vs. $140-$ $179 \mathrm{~mm} \mathrm{Hg}$ within 4.5 hours of ICH onset. Because of futility, the trial was early terminated after enrolling 1,000 patients. Between the SBP 110-139 mm Hg and 140-179 mm Hg groups, there was no difference in the primary endpoint of 90day mRS 4-6 (38.7\% vs. $37.7 \%$, RR $1.04,95 \% \mathrm{Cl} 0.85-1.27)$ and the rate of hematoma expansion $>33 \%$ at 24 hours (18.9\% vs. $24.4 \% ; 0.78,0.58-1.03)$. The intensive BP lowering group had more renal adverse events within 7 days (9.0\% vs. $4.0 \%$, $P=0.002$ ). The achieved SBP at 2-3 hours after randomization was around $120 \mathrm{~mm} \mathrm{Hg}$ in the intensive arm and $140 \mathrm{~mm} \mathrm{Hg}$ in the standard arm. Therefore, the ATACH-2 results suggest that a desirable SBP target would be $140 \mathrm{~mm} \mathrm{Hg}$ and very aggressive SBP lowering down to $120 \mathrm{~mm} \mathrm{Hg}$ seems unnecessary. ${ }^{83}$

\section{Summary}

RCTs confirmed the epidemiologically expected benefits of BP lowering for the prevention of stroke and major cardiovascular events. Among several antihypertensive classes, which one is better for stroke prevention is still less clear, and adequate BP lowering is of great importance. Regarding intensive or less intensive BP lowering for primary stroke prevention, accumulated evidences favor intensive lowering. However, caution is needed to minimize the risk of adverse events. For secondary stroke prevention, the evidence supporting intensive BP lowering over less intensive BP lowering is limited and indirect, particularly patients with stroke due to large artery atherosclerosis. However, in patients with small vessel occlusion, SPB target $<130 \mathrm{~mm} \mathrm{Hg}$ is like- ly more beneficial based on data from a single large RCT. Therefore more RCTs testing BP target for secondary stroke prevention are eagerly needed. In acute $\mathrm{ICH}$, the evidence from RCTs supports the immediate BP lowering targeting $\mathrm{SBP}<140 \mathrm{~mm} \mathrm{Hg}$, which is now recommended by guidelines. However, in acute ischemic stroke, large RCTs did not demonstrate the benefit of early BP lowering, but suggested an increased risk early neurological deterioration. Therefore, otherwise indicated, it would be better to delay BP lowering in acute ischemic stroke.

\section{References}

1. WHO. A global brief on hypertension. Geneva: World Health Organization, 2013.

2. O'Donnell MJ, Chin SL, Rangarajan $S$, Xavier D, Liu L, Zhang H, et al. Global and regional effects of potentially modifiable risk factors associated with acute stroke in 32 countries (INTERSTROKE): a case-control study. Lancet 2016;388:761-775.

3. Lewington $S$, Clarke R, Qizilbash N, Peto R, Collins R; Prospective Studies Collaboration. Age-specific relevance of usual blood pressure to vascular mortality: a meta-analysis of individual data for one million adults in 61 prospective studies. Lancet 2002;360:1903-1913.

4. Lawes CM, Rodgers A, Bennett DA, Parag V, Suh I, Ueshima $H$, et al. Blood pressure and cardiovascular disease in the Asia Pacific region. J Hypertens 2003;21:707-716.

5. MacMahon S, Peto R, Cutler J, Collins R, Sorlie P, Neaton J, et al. Blood pressure, stroke, and coronary heart disease. Part 1 , prolonged differences in blood pressure: prospective observational studies corrected for the regression dilution bias. Lancet 1990;335:765-774.

6. Rothwell PM, Coull AJ, Giles MF, Howard SC, Silver LE, Bull LM, et al. Change in stroke incidence, mortality, case-fatality, severity, and risk factors in Oxfordshire, UK from 1981 to 2004 (Oxford Vascular Study). Lancet 2004;363:1925-1933.

7. Carandang R, Seshadri S, Beiser A, Kelly-Hayes M, Kase CS, Kannel $W B$, et al. Trends in incidence, lifetime risk, severity, and 30-day mortality of stroke over the past 50 years. JAMA 2006;296:2939-2946.

8. Lackland DT, Roccella EJ, Deutsch AF, Fornage M, George MG, Howard $\mathrm{G}$, et al. Factors influencing the decline in stroke mortality: a statement from the American Heart Association/ American Stroke Association. Stroke 2014;45:315-353.

9. Kubo M, Kiyohara Y, Kato I, Tanizaki Y, Arima H, Tanaka K, et al. Trends in the incidence, mortality, and survival rate of cardiovascular disease in a Japanese community: the Hisayama study. Stroke 2003;34:2349-2354. 
10. James PA, Oparil S, Carter BL, Cushman WC, Dennison-Himmelfarb C, Handler J, et al. 2014 evidence-based guideline for the management of high blood pressure in adults: report from the panel members appointed to the Eighth Joint National Committee (JNC 8). JAMA 2014;311:507-520.

11. Dong C, Della-Morte D, Rundek T, Wright CB, Elkind MS, Sacco RL. Evidence to maintain the systolic blood pressure treatment threshold at $140 \mathrm{~mm} \mathrm{Hg}$ for stroke prevention: the Northern Manhattan Study. Hypertension 2016;67:520-526.

12. Psaty BM, Lumley $T$, Furberg $C D$, Schellenbaum $G$, Pahor $M$, Alderman $\mathrm{MH}$, et al. Health outcomes associated with various antihypertensive therapies used as first-line agents: a network meta-analysis. JAMA 2003;289:2534-2544.

13. Law MR, Morris JK, Wald NJ. Use of blood pressure lowering drugs in the prevention of cardiovascular disease: meta-analysis of 147 randomised trials in the context of expectations from prospective epidemiological studies. BMJ 2009;338: b1665.

14. Ettehad D, Emdin CA, Kiran A, Anderson SG, Callender T, Emberson J, et al. Blood pressure lowering for prevention of cardiovascular disease and death: a systematic review and metaanalysis. Lancet 2016;387:957-967.

15. Hansson L, Lindholm LH, Ekbom $T$, Dahlöf B, Lanke J, Scherstén $B$, et al. Randomised trial of old and new antihypertensive drugs in elderly patients: cardiovascular mortality and morbidity the Swedish trial in old patients with hypertension-2 study. Lancet 1999;354:1751-1756.

16. Hansson L, Lindholm LH, Niskanen L, Lanke J, Hedner T, Niklason $A$, et al. Effect of angiotensin-converting-enzyme inhibition compared with conventional therapy on cardiovascular morbidity and mortality in hypertension: the captopril prevention project (CAPPP) randomised trial. Lancet 1999;353: 611-616.

17. Brown MJ, Palmer CR, Castaigne A, de Leeuw PW, Mancia G,

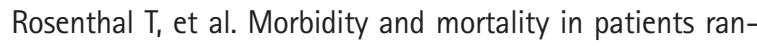
domised to double-blind treatment with a long-acting calcium-channel blocker or diuretic in the International Nifedipine GITS study: intervention as a goal in hypertension treatment (INSIGHT). Lancet 2000;356:366-372.

18. Hansson L, Hedner T, Lund-Johansen P, Kjeldsen SE, Lindholm LH, Syvertsen JO, et al. Randomised trial of effects of calcium antagonists compared with diuretics and beta-blockers on cardiovascular morbidity and mortality in hypertension: the Nordic Diltiazem (NORDIL) study. Lancet 2000;356:359-365.

19. Dahlöf $B$, Devereux RB, Kjeldsen $S E$, Julius $S$, Beevers $G$, de Faire $U$, et al. Cardiovascular morbidity and mortality in the losartan intervention for endpoint reduction in hypertension study (LIFE): a randomised trial against atenolol. Lancet 2002;
359:995-1003.

20. Dahlöf B, Sever PS, Poulter NR, Wedel H, Beevers DG, Caulfield $M$, et al. Prevention of cardiovascular events with an antihypertensive regimen of amlodipine adding perindopril as required versus atenolol adding bendroflumethiazide as required, in the anglo-scandinavian cardiac outcomes trialblood pressure lowering arm (ASCOT-BPLA): a multicentre randomised controlled trial. Lancet 2005;366:895-906.

21. Major cardiovascular events in hypertensive patients randomized to doxazosin vs chlorthalidone: the antihypertensive and lipid-lowering treatment to prevent heart attack trial (ALLHAT). ALLHAT Collaborative Research Group. JAMA 2000; 283:1967-1975.

22. ALLHAT Officers and Coordinators for the ALLHAT Collaborative Research Group, The Antihypertensive and Lipid-Lowering Treatment to Prevent Heart Attack Trial. Major outcomes in high-risk hypertensive patients randomized to angiotensinconverting enzyme inhibitor or calcium channel blocker vs diuretic: the antihypertensive and lipid-lowering treatment to prevent heart attack trial (ALLHAT). JAMA 2002;288:29812997.

23. Jamerson $K$, Weber MA, Bakris GL, Dahlöf B, Pitt B, Shi V, et al. Benazepril plus amlodipine or hydrochlorothiazide for hypertension in high-risk patients. N Engl J Med 2008;359: 2417-2428.

24. Matsuzaki M, Ogihara $T$, Umemoto $S$, Rakugi $H$, Matsuoka $H$, Shimada $K_{1}$ et al. Prevention of cardiovascular events with calcium channel blocker-based combination therapies in patients with hypertension: a randomized controlled trial. J Hypertens 2011;29:1649-1659.

25. Grau A, Weimar C, Buggle F, Heinrich A, Goertler M, Neumaier $\mathrm{S}$, et al. Risk factors, outcome, and treatment in subtypes of ischemic stroke: the German stroke data bank. Stroke 2001;32:2559-2566.

26. Kimura K, Kazui S, Minematsu K, Yamaguchi T; Japan Multicenter Stroke Investigator's Collaboration. Analysis of 16,922 patients with acute ischemic stroke and transient ischemic attack in Japan. A hospital-based prospective registration study. Cerebrovasc Dis 2004;18:47-56.

27. Fonarow GC, Reeves MJ, Smith EE, Saver JL, Zhao X, Olson DW, et al. Characteristics, performance measures, and inhospital outcomes of the first one million stroke and transient ischemic attack admissions in get with the guidelines-stroke. Circ Cardiovasc Qual Outcomes 2010;3:291-302.

28. Kim BJ, Park JM, Kang K, Lee SJ, Ko Y, Kim JG, et al. Case characteristics, hyperacute treatment, and outcome information from the clinical research center for stroke-fifth division registry in South Korea. J Stroke 2015;17:38-53. 
29. Carter AB. Hypotensive therapy in stroke survivors. Lancet 1970;1:485-489.

30. Effect of antihypertensive treatment on stroke recurrence. Hypertension-Stroke Cooperative Study Group. JAMA 1974; 229:409-418.

31. Trial of secondary prevention with atenolol after transient ischemic attack or nondisabling ischemic stroke. The Dutch TIA Trial Study Group. Stroke 1993;24:543-548.

32. Eriksson S, Olofsson BO, Wester PO. Atenolol in secondary prevention after stroke. Cerebrovasc Dis 1995;5:21-25.

33. PATS Collaborating Group. Post-stroke antihypertensive treatment study. A preliminary result. Chin Med J (Engl) 1995;108: 710-717.

34. Liu L, Wang $Z$, Gong $L$, Zhang $Y$, Thijs $L$, Staessen JA, et al. Blood pressure reduction for the secondary prevention of stroke: a Chinese trial and a systematic review of the literature. Hypertens Res 2009;32:1032-1040.

35. PROGRESS Collaborative Group. Randomised trial of a perindopril-based blood-pressure-lowering regimen among 6,105 individuals with previous stroke or transient ischaemic attack. Lancet 2001;358:1033-1041.

36. Rashid P, Leonardi-Bee J, Bath P. Blood pressure reduction and secondary prevention of stroke and other vascular events: a systematic review. Stroke 2003;34:2741-2748.

37. Yusuf S, Diener HC, Sacco RL, Cotton D, Ounpuu S, Lawton $W A$, et al. Telmisartan to prevent recurrent stroke and cardiovascular events. N Engl J Med 2008;359:1225-1237.

38. Katsanos $A H$, Filippatou A, Manios E, Deftereos S, Parissis J, Frogoudaki $A$, et al. Blood pressure reduction and secondary stroke prevention: a systematic review and metaregression analysis of randomized clinical trials. Hypertension 2017; 69:171-179.

39. Towfighi A, Markovic D, Ovbiagele B. Consistency of blood pressure control after ischemic stroke: prevalence and prognosis. Stroke 2014;45:1313-1317.

40. Ovbiagele $B$, Diener HC, Yusuf $S$, Martin RH, Cotton D, Vinisko $\mathrm{R}$, et al. Level of systolic blood pressure within the normal range and risk of recurrent stroke. JAMA 2011;306:21372144.

41. Rothwell PM, Howard SC, Spence JD; Carotid Endarterectomy Trialists' Collaboration. Relationship between blood pressure and stroke risk in patients with symptomatic carotid occlusive disease. Stroke 2003;34:2583-2590.

42. Chaturvedi S, Turan TN, Lynn MJ, Kasner SE, Romano J, Cotsonis $\mathrm{G}$, et al. Risk factor status and vascular events in patients with symptomatic intracranial stenosis. Neurology 2007;69:2063-2068.

43. Turan TN, Lynn MJ, Nizam A, Lane B, Egan BM, Le NA, et al.
Rationale, design, and implementation of aggressive risk factor management in the stenting and aggressive medical management for prevention of recurrent stroke in intracranial stenosis (SAMMPRIS) trial. Circ Cardiovasc Qual Outcomes 2012;5:e51-e60.

44. Turan TN, Nizam A, Lynn MJ, Egan BM, Le NA, Lopes-Virella $M F$, et al. Relationship between risk factor control and vascular events in the SAMMPRIS trial. Neurology 2017;88:379385.

45. Waters MF, Hoh BL, Lynn MJ, Kwon HM, Turan TN, Derdeyn $\mathrm{CP}$, et al. Factors associated with recurrent ischemic stroke in the medical group of the SAMMPRIS Trial. JAMA Neurol 2016;73:308-315.

46. Messerli FH, Mancia G, Conti CR, Hewkin AC, Kupfer S, Cham-

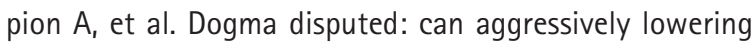
blood pressure in hypertensive patients with coronary artery disease be dangerous? Ann Intern Med 2006;144:884-893.

47. Sleight $P$, Redon J, Verdecchia $P$, Mancia G, Gao P, Fagard R, et al. Prognostic value of blood pressure in patients with high vascular risk in the ongoing telmisartan alone and in combination with ramipril global endpoint trial study. $J$ Hypertens 2009;27:1360-1369.

48. ACCORD Study Group, Cushman WC, Evans GW, Byington RP, Goff DC Jr, Grimm RH Jr, et al. Effects of intensive bloodpressure control in type 2 diabetes mellitus. N Engl J Med 2010;362:1575-1585.

49. Bangalore S, Kumar S, Lobach I, Messerli FH. Blood pressure targets in subjects with type 2 diabetes mellitus/impaired fasting glucose: observations from traditional and bayesian random-effects meta-analyses of randomized trials. Circulation 2011;123:2799-2810, 9 p following 2810.

50. Fan F, Yuan Z, Qin X, Li J, Zhang Y, Li Y, et al. Optimal systolic blood pressure levels for primary prevention of stroke in general hypertensive adults: findings from the CSPPT (China stroke primary prevention trial). Hypertension 2017;69:697704.

51. Lee M, Saver JL, Hong KS, Hao Q, Ovbiagele B. Does achieving an intensive versus usual blood pressure level prevent stroke? Ann Neurol 2012;71:133-140.

52. Xie $X$, Atkins E, Lv J, Bennett A, Neal B, Ninomiya T, et al. Effects of intensive blood pressure lowering on cardiovascular and renal outcomes: updated systematic review and metaanalysis. Lancet 2016;387:435-443.

53. SPRINT Research Group, Wright JT Jr, Williamson JD, Whelton PK, Snyder JK, Sink KM, et al. A randomized trial of intensive versus standard blood-pressure control. N Engl J Med 2015; 373:2103-2116.

54. Perkovic V, Rodgers A. Redefining blood-pressure targets-- 
SPRINT starts the marathon. N Engl J Med 2015;373:21752178.

55. Lonn EM, Bosch J, López-Jaramillo P, Zhu J, Liu L, Pais P, et al. Blood-pressure lowering in intermediate-risk persons without cardiovascular disease. N Engl J Med 2016;374:2009-2020.

56. Arima $H$, Chalmers J, Woodward M, Anderson C, Rodgers A, Davis $S$, et al. Lower target blood pressures are safe and effective for the prevention of recurrent stroke: the PROGRESS trial. J Hypertens 2006;24:1201-1208.

57. Turan TN, Cotsonis G, Lynn MJ, Chaturvedi S, Chimowitz M; Warfarin-Aspirin Symptomatic Intracranial Disease (WASID) Trial Investigators. Relationship between blood pressure and stroke recurrence in patients with intracranial arterial stenosis. Circulation 2007;115:2969-2975.

58. Powers WJ, Clarke WR, Grubb RL Jr, Videen TO, Adams HP Jr, Derdeyn $\mathrm{CP}$, et al. Lower stroke risk with lower blood pressure in hemodynamic cerebral ischemia. Neurology 2014;82:10271032.

59. Amin-Hanjani S, Turan TN, Du X, Pandey DK, Rose-Finnell L, Richardson $D$, et al. Higher stroke risk with lower blood pressure in hemodynamic vertebrobasilar disease: analysis from the VERiTAS study. J Stroke Cerebrovasc Dis 2017;26:403-410.

60. SPS3 Study Group, Benavente OR, Coffey CS, Conwit R, Hart $R G, M c C l u r e ~ L A$, et al. Blood-pressure targets in patients with recent lacunar stroke: the SPS3 randomised trial. Lancet 2013;382:507-515.

61. Kernan WN, Ovbiagele B, Black HR, Bravata DM, Chimowitz $M I$, Ezekowitz MD, et al. Guidelines for the prevention of stroke in patients with stroke and transient ischemic attack: a guideline for healthcare professionals from the American Heart Association/American Stroke Association. Stroke 2014; 45:2160-2236.

62. Qureshi Al, Ezzeddine MA, Nasar A, Suri MF, Kirmani JF, Hussein HM, et al. Prevalence of elevated blood pressure in 563,704 adult patients with stroke presenting to the ED in the United States. Am J Emerg Med 2007;25:32-38.

63. Leonardi-Bee J, Bath PM, Phillips SJ, Sandercock PA; IST Collaborative Group. Blood pressure and clinical outcomes in the international stroke trial. Stroke 2002;33:1315-1320.

64. Schrader J, Lüders S, Kulschewski A, Berger J, Zidek W, Treib J, et al. The ACCESS study: evaluation of acute candesartan cilexetil therapy in stroke survivors. Stroke 2003;34:1699-1703.

65. Potter JF, Robinson TG, Ford GA, Mistri A, James M, Chernova $J$, et al. Controlling hypertension and hypotension immediately post-stroke (CHHIPS): a randomised, placebo-controlled, double-blind pilot trial. Lancet Neurol 2009;8:48-56.

66. Sandset EC, Bath PM, Boysen G, Jatuzis D, Kõrv J, Lüders $S$, et al. The angiotensin-receptor blocker candesartan for treat- ment of acute stroke (SCAST): a randomised, placebo-controlled, double-blind trial. Lancet 2011;377:741-750.

67. Oh MS, Yu KH, Hong KS, Kang DW, Park JM, Bae HJ, et al. Modest blood pressure reduction with valsartan in acute ischemic stroke: a prospective, randomized, open-label, blinded-end-point trial. Int J Stroke 2015;10:745-751.

68. Jusufovic M, Sandset EC, Bath PM, Karlson BW, Berge E; Scandinavian Candesartan Acute Stroke Trial Study Group. Effects of blood pressure lowering in patients with acute ischemic stroke and carotid artery stenosis. Int J Stroke 2015; 10:354-359.

69. He J, Zhang Y, Xu T, Zhao Q, Wang D, Chen CS, et al. Effects of immediate blood pressure reduction on death and major disability in patients with acute ischemic stroke: the CATIS randomized clinical trial. JAMA 2014;311:479-489.

70. Lee $M$, Ovbiagele $B$, Hong $K S, W u Y L$, Lee JE, Rao NM, et al. Effect of blood pressure lowering in early ischemic stroke: meta-analysis. Stroke 2015;46:1883-1889.

71. Jauch EC, Saver JL, Adams HP Jr, Bruno A, Connors JJ, Demaerschalk BM, et al. Guidelines for the early management of patients with acute ischemic stroke: a guideline for healthcare professionals from the American Heart Association/ American Stroke Association. Stroke 2013;44:870-947.

72. TIMI Study Group. Comparison of invasive and conservative strategies after treatment with intravenous tissue plasminogen activator in acute myocardial infarction. Results of the thrombolysis in myocardial infarction (TIMI) phase II trial. $N$ Engl J Med 1989;320:618-627.

73. GUSTO investigators. An international randomized trial comparing four thrombolytic strategies for acute myocardial infarction. N Engl J Med 1993;329:673-682.

74. Wahlgren N, Ahmed N, Eriksson N, Aichner F, Bluhmki $E_{\text {, }}$ Dávalos $A$, et al. Multivariable analysis of outcome predictors and adjustment of main outcome results to baseline data profile in randomized controlled trials: safe Implementation of thrombolysis in stroke-monitoring study (SITS-MOST). Stroke 2008;39:3316-3322.

75. Ahmed N, Wahlgren N, Brainin M, Castillo J, Ford GA, Kaste $M$, et al. Relationship of blood pressure, antihypertensive therapy, and outcome in ischemic stroke treated with intravenous thrombolysis: retrospective analysis from safe implementation of thrombolysis in stroke-international stroke thrombolysis register (SITS-ISTR). Stroke 2009;40:2442-2449.

76. Huang Y, Sharma VK, Robinson T, Lindley RI, Chen X, Kim JS, et al. Rationale, design, and progress of the enhanced control of hypertension and thrombolysis stroke study (ENCHANTED) trial: an international multicenter $2 \times 2$ quasi-factorial randomized controlled trial of low- vs. standard-dose rt-PA and 
early intensive vs. guideline-recommended blood pressure lowering in patients with acute ischaemic stroke eligible for thrombolysis treatment. Int J Stroke 2015;10:778-788.

77. Martins Al, Sargento-Freitas J, Silva F, Jesus-Ribeiro J, Correia I, Gomes JP, et al. Recanalization modulates association between blood pressure and functional outcome in acute ischemic stroke. Stroke 2016;47:1571-1576.

78. Hemphill JC 3rd, Greenberg SM, Anderson CS, Becker K, Bendok BR, Cushman $M$, et al. Guidelines for the management of spontaneous intracerebral hemorrhage: a guideline for healthcare professionals from the American Heart Association/American Stroke Association. Stroke 2015;46:20322060.

79. Steiner T, Al-Shahi Salman R, Beer R, Christensen H, Cordonnier C, Csiba L, et al. European stroke organisation (ESO) guidelines for the management of spontaneous intracerebral hemorrhage. Int J Stroke 2014;9:840-855.

80. Anderson CS, Huang Y, Wang JG, Arima H, Neal B, Peng B, et al. Intensive blood pressure reduction in acute cerebral haemorrhage trial (INTERACT): a randomised pilot trial. Lancet Neurol 2008;7:391-399.

81. Antihypertensive Treatment of Acute Cerebral Hemorrhage (ATACH) investigators. Antihypertensive treatment of acute cerebral hemorrhage. Crit Care Med 2010;38:637-648.

82. Anderson CS, Heeley E, Huang Y, Wang J, Stapf C, Delcourt C, et al. Rapid blood-pressure lowering in patients with acute intracerebral hemorrhage. N Engl J Med 2013;368:2355-2365.

83. Qureshi Al, Palesch YY, Barsan WG, Hanley DF, Hsu CY, Martin $\mathrm{RL}$, et al. Intensive blood-pressure lowering in patients with acute cerebral hemorrhage. N Engl J Med 2016;375:10331043. 